\title{
Development of Voltage Fields in Titanium VT1-0 while Forming a Thin Wedge-Shaped Twin
}

\author{
Nikolai V. Kamyshanchenko, Alexander V. Gal'tsev, Vladimir A. Belenko, Tatyana B. \\ Nikulicheva
}

\begin{abstract}
In the selected treatment modes, a thin wedge-shaped twin was observed, it passed through a section of the crystal with a weak concentration of visible defects. Additional etching of the titanium film revealed an ordered arrangement of dislocations with contrast that appeared on the surface inside the circular sites, which are the stacking faults inside the dislocation loop. The authors provide an explanation of the formation of stacking faults using the detected oscillating contrasts of the faults that are close to the surface. The voltage fields around the wedge-shaped twin, which were constructed with the use of computer simulation, made it possible to determine the value of the elastic stress when it comes into contact with the stopper.
\end{abstract}

Keywords: Twinning; titanium; treatment mode; wedge-shaped twin; dislocation loops; stacking fault.

\section{INTRODUCTION}

Twinning refers to the main types of deformation of crystals with a HCP structure and, unlike sliding, this type of plastic deformation depends on many factors affecting this structure. The objective laws of the dependence of twinning process, twins' mobility in the crystal on the conditions of external energy influences, for example, in the works [1,2], are established.

Since at plastic deformation over 30\% fragmentation mainly occurs due to twinning that depends on the orientation of individual crystals the creation of a homogeneous substructure is possible with subsequent annealing at temperatures exceeding the temperature of plastic deformation. For titanium the effective plastic deformation temperature is $500^{\circ} \mathrm{C}$, and the effective annealing temperature is $700-800^{\circ} \mathrm{C}$. X-ray diffraction analysis shows that at such temperature conditions and accumulated deformation $\varepsilon=70 \%$ technically pure titanium of VT1-0 brand is a stable $\alpha$-modification and HCP-structure [3].

The deformability of individual crystals due to such mechanisms as sliding and twinning within the grain of the investigated titanium depends on the selected orientation, purity and grain size [4].

Revised Manuscript Received on September 22, 2019

* Correspondence Author

Nikolai V. Kamyshanchenko, Belgorod State University, Russia, 308015, Belgorod, Pobedy st., 85

Alexander V. Gal'tsev, Belgorod State University, Russia, 308015 , Belgorod, Pobedy st., 85

Vladimir A. Belenko, Belgorod State University, Russia, 308015, Belgorod, Pobedy st., 85

Tatyana B. Nikulicheva, Belgorod State University, Russia, 308015, Belgorod, Pobedy st., 85
As a result of high anisotropy the contribution of each of these mechanisms to the properties depends on the local stress state [5].

Since at the temperature of $700^{\circ} \mathrm{C}$ in plastically deformed titanium up to $\varepsilon=75 \%$ the formation of twins is detected with great difficulty [6], the state of the dislocation field, which is created by residual internal stresses, in the absence of external influence, under these processing modes, is of particular interest.

\section{SETTING THE EXPERIMENT}

The study of the distribution mechanism of elastic twins was carried out on titanium [7] (GOST 26422-85) brand VT1-0 at room temperature.

To obtain the material in the fine-grained state titanium billets were rolled on electromechanical rollers at the temperature of $500^{\circ} \mathrm{C}$ by plastic deformation in several passes to a thickness of $1.5 \mathrm{~mm}$ with a residual deformation value of $\varepsilon=75 \%$. X-ray analysis showed that after such pretreatment titanium represents a stable $\alpha$-modification of the HCP lattice. According to available studies, deformation of polycrystalline $\alpha-\mathrm{Ti}$ is carried out mainly by sliding along the prismatic planes $\{\overline{1} 012\}$ and, as a secondary, along the pyramidal planes $\{10 \overline{1} 1\}$ и $\{\overline{1} 012\}$. Sliding along these planes develops along densely packed directions $<1210\}>$ lying in the plane of the basis [8].

To identify grain boundaries, the samples were chemically etched in a solution containing $1 \mathrm{ml}$ of $\mathrm{HNO}_{3} .2 \mathrm{ml} \mathrm{HF}$ and 40 $\mathrm{ml} \mathrm{H}_{2} \mathrm{O}$. the Morphology of the samples surface was studied with the use of a microscope "OLYMPUS GX51". Determination of average grain sizes was carried out by the "random- secant" method according to GOST 5639-82.

The microstructure of the sample was studied with the use of a transmission electron microscope "JEM-2100", equipped with $200 \mathrm{KV}$ electron gun. The samples were thinned mechanically on a grinding and polishing machine "Strues LadoPol" to a thickness of $110 \mathrm{mk}$. The resulting foil was used to produce discs with a diameter of $3 \mathrm{~mm}$ followed by electric polishing on the unit "Strues TenuPol-5". The samples were electro-polished in electrolyte $(5 \mathrm{ml}$ perchloric acid and $95 \mathrm{ml}$ methanol) at voltage $\mathrm{U}=30 \mathrm{~V}$ and temperature $\left(-40^{\circ} \mathrm{C}\right)$. Annealing was carried out at the temperature of $700^{\circ} \mathrm{C}$ in a vacuum furnace with a residual pressure in the chamber not lower than $10^{-5} \mathrm{~Pa}$.

!!!Выделенные маркировки не нашла на англ. По правилам нужно оставить на русском - Решение за вами.

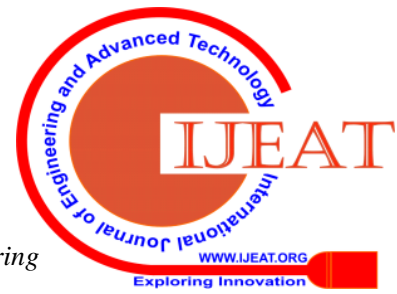




\section{FINDINGS AND DISCUSSION}

After rolling to the total degree of deformation $\varepsilon=75 \%$ in the structure of Ti texture fragments of extended shape from 1 to 10 microns in size are observed. After annealing at the temperature of $700^{\circ} \mathrm{C}$, an inhomogeneous grain structure with a grain size from 12 to 50 microns is formed. Within small grains, twinning is a difficult to detect since it is impossible to create an inhomogeneous distribution of internal stresses. Besides, annealing reduces the density of deformation defects. The detected residual twins were observed in the areas where the dislocation density is low and a thin twin wedge moves along a narrow strip of material crystal или crystalline material that is free from dislocations (Fig.1.a, b).

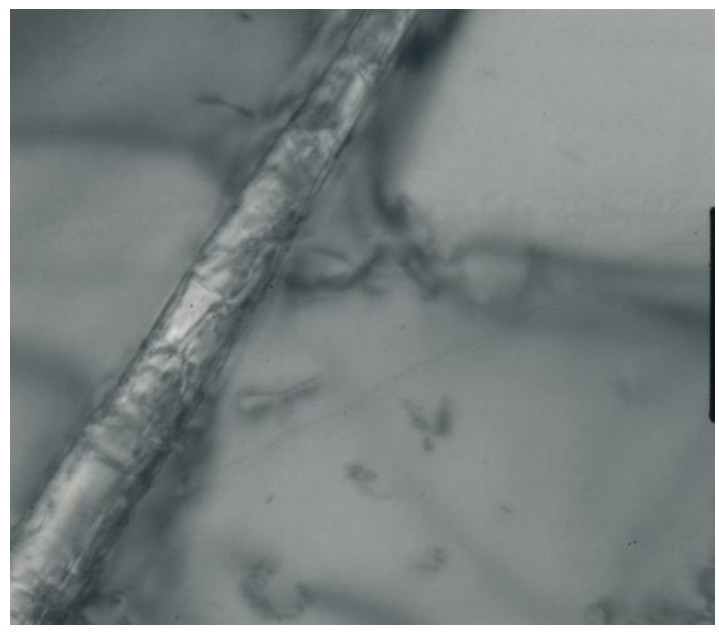

a)

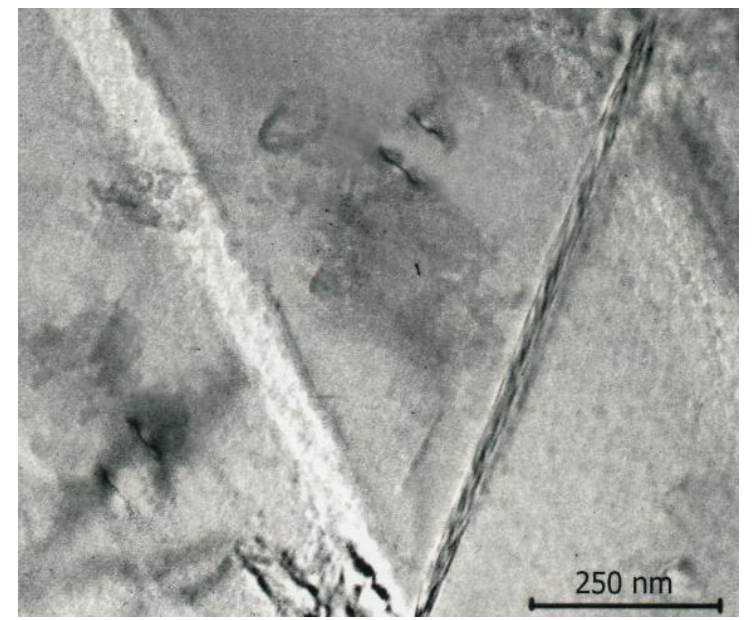

b)

Figure 1: The results of transmission microscopy of the sample VT1-0. a) dislocation field in Ti along the plane of twin layer. b) position of the wedge-shaped mechanical twin

in the area of twinning plane. The mark in the photo corresponds to $250 \mathrm{~nm}$.

When the elastic twin moves on the crystal surface under the influence of internal stresses, it meets an obstacle in the form of a twin plane of another orientation, which leads to the wedge-shaped crystal growth cessation (Fig. 1.bel.) However, the thickness of the thin wedge-shaped twin does not increase. The twin jamming in the crystal is obviously due to the emergence of obstacles on more powerful defects, which is, in this case, a twin layer of a different orientation. The twin spreads over the crystal area without significant overcoming any visible defects. Etching of the thinned plate revealed a pattern of lattice defects distribution on the crystal surface (Fig. 2).

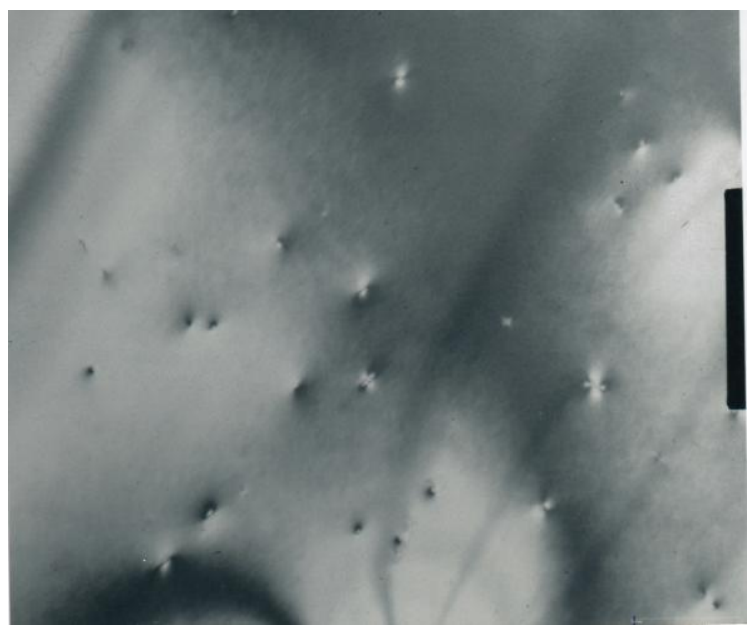

Figure 2. Defective structure of the sample after etching in the dark-field image. The mark in the photo corresponds to $250 \mathrm{~nm}$.

The oscillating contrast, which is formed by dislocations and revealed by etching, gradually approaches the crystal surface, and the presence of a volume association of dislocations resembles a twin layer (Fig.3). In the areas free from internal stresses, the surface state of the lattice structure is a parallel row of dislocations that have come to the surface. The defects arranged in a chain in each parallel row represent dislocation loops with stacking faults of vacancy type (Fig. 2).

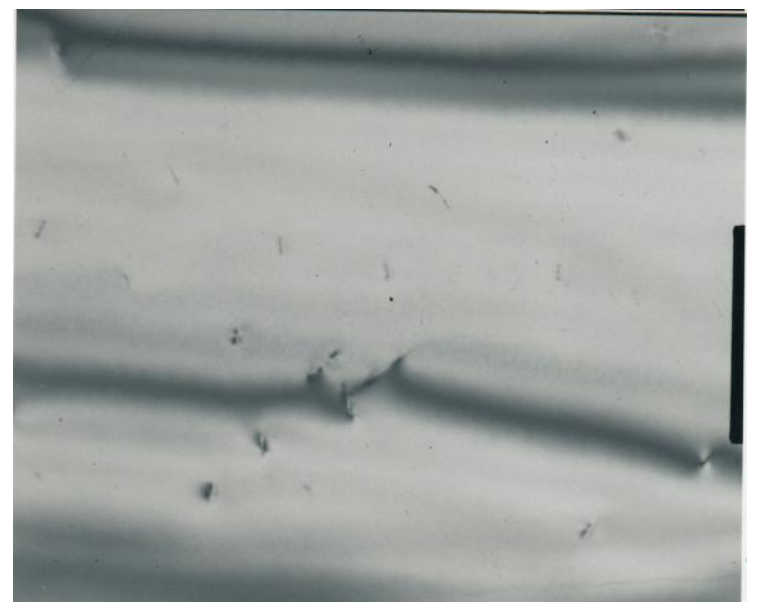

Figure 3. Oscillating contrast of a crystal defect close to the surface in a light-field image. The mark in the photo corresponds to $250 \mathrm{~nm}$.

Evidently, stacking faults can be formed as a result of changes in the thickness of the foil, which corresponds to the creation of conditions for mutual intersection of two dislocations located at different levels of the structure (Fig.3), or cross sliding to form steps of different sizes [9]. Similar stretched steps formed by cross sliding were found in single-crystal scales of tin disulfite [10].

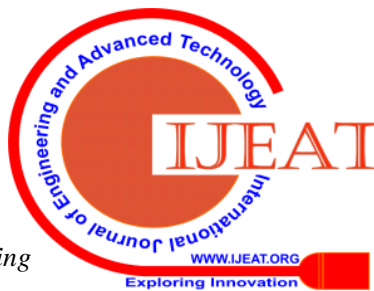




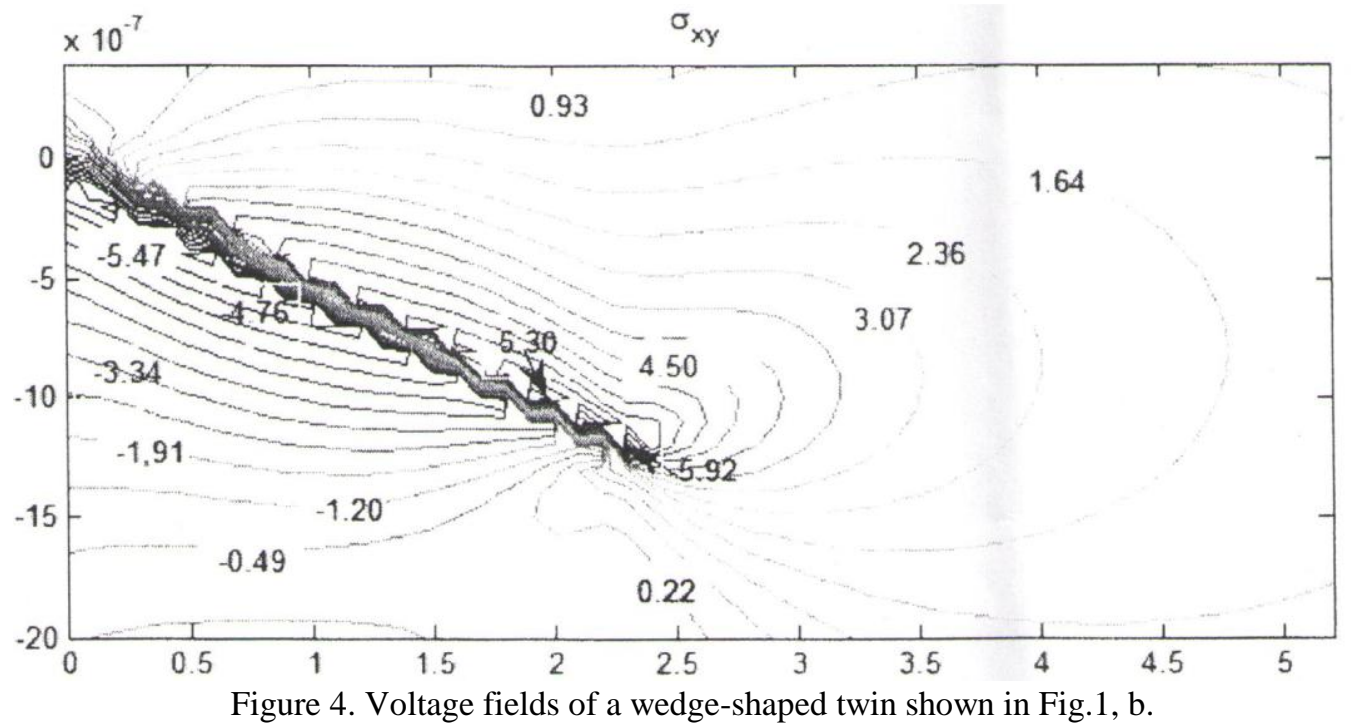

Development of a wedge-shaped twin and formation of defects in the surface layers of the crystal, obviously, occur as a result of internal stresses.

The voltage field near the wedge-shaped twin was determined by analogy with the technique described in [11].

$$
\begin{aligned}
& \sigma_{i j}(x, y)= \\
& \sum_{i=1}^{4} \int_{0}^{L} \sqrt{1+\left(f_{i}^{0}\left(x_{0}\right)\right)^{2}} \rho_{i}\left(x_{0}\right) \sigma_{x y}^{(i, 0)}\left(x, y, x_{0}\right) d x_{0}
\end{aligned}
$$

where L - length of the twin; $f_{i}\left(x_{0}\right)$ - functions describing the shape of the boundaries of the wedge-shaped twin (Fig.1); $\rho_{\mathrm{i}}\left(x_{0}\right)$ - densities of twinning dislocations at the boundaries of the twin; $\sigma_{x y}^{[i 0]}$ - stresses created at the twin boundaries by individual dislocations.

Fig. 4 shows that the stresses increase when approaching the twin boundary, and at the twin top they have the same order as in the immediate vicinity of the twin boundary.

The influence of the field created by the mechanical twin is observed on the surface of the structural system of the titanium lattice in the form of a dislocation chain (Fig.2), discovered by this experience.

In the process of formation of a wedge-shaped twin, in the area near it the formed vacancies are united or absorbed to form large stable defects. Such associations are possible at large ratios $C_{v / C_{i}}$, at which the process of homogeneous nucleation prevails [12]. Here $C_{v}$ и $C_{i}$ are respectively vacancies density and foreign atoms density. At low values of $C_{V} /_{C_{i}}$ the process of heterogeneous nucleation will be a predominant mechanism. Defects density after wedge-shaped twin passing, as shown by experience, reduces significantly (Fig. 1). The question arises: how are the loops formed, what determines the nature of their distribution along the chain?

The distribution of the secretions shown in Fig. 2 in the form of projections or depressions perpendicular to the crystal surface, according to the configuration corresponds to dislocation loops with stacking faults. In the predominant majority in such loops there is a contrast inside the circular pads, which are stacking faults inside the dislocation loop. The direction of Burgers vector in such loops coincides with the direction (0001).
Early studies of the structure on dislocation-free zinc plates [13] showed that formation and growth of loops in the basal plane of perfect cadmium plates, which are grown by sublimation [14], as well as dislocation processes in zinc under cold deformation [15], occur due to the emergence of such loops with defects mainly by the effect of vacancies, which are formed behind moving screw dislocations.

Dislocation loops lie in the base plane and are formed by screw dislocations with a Buegers vector [1 $1 \overline{1} 23]$ and plane sliding [112 2 ], which undergo double transverse sliding . In this case, two types of dislocation loops are formed , which give a different contrast . Loops of the first type have a

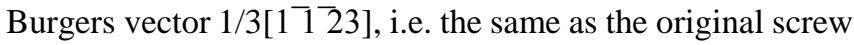
dislocation has. Loop of the first type have a Burgers vector [0001] and such loops are formed from loops of the first type according to the reaction equation.

$$
1 / 3[\overline{11} 23] \rightarrow 1 / 3[\overline{1} \overline{1} 20]+[0001]
$$

The first component on the right is a sliding loop and disappears as a result of sliding along the basal plane.

When dislocation loops move, they come into contact in the same or adjacent planes of the crystal lattice. In this case, areas of dislocation loops always have components of the opposite sign. During interaction of two dislocation loops, various variants are observed [16]: growth of loops is possible or, on the contrary, division into two partial dislocations, between which there is a stacking fault, etc. (Fig. 3).

It is known that in the boundary zones of the residual wedge-shaped twin large elastic stresses of the stopper are localized and the level of their voltage fields becomes sufficient for formation of dislocation loops. This stage seems to be shown in Fig.1, where there are places with a small concentration of defects or they are absent.

\section{CONCLUSION}

1. Since the wedge-shaped twin does not thicken after reaching the insurmountable stopper, it can be assumed that the internal stress is weak and the density of twin dislocations is insufficient. 
2. When the twin layer is wedged, there is such a value of elastic stresses in the twin contact zone with the parent crystal, that the emergence of loops occurs everywhere in the volume along the twin and it is convenient to observe them after additional etching of the titanium film in the form of well-spaced dislocation chains.

3. When dislocation loops move, they come into contact in the same or adjacent planes of the crystal lattice. When such two dislocation loops interact, different options are possible: growth of the loops or, conversely, division into two partial dislocations containing stacking faults.

4. The voltage fields formed by wedge-type twinning increase while approaching the twin boundary. Moreover, at the twin top they have the same order as in the immediate vicinity to the top of the twin boundary, but with higher stresses. As a result of the formed internal stress around the wedge-shaped twin, defects move and the probability of new structural defects in the crystal increases.

The authors express their gratitude to post-graduate students Kungurtsev E.S. and Kungurtsev M.S. for their interest in work.

\section{REFERENCES}

1. Savenko, V.S., Tsebric, M.S., 1980. Izvestiia AN BSSR. Series Phys. Math. Sciences, 1: 105-108 (In Russian).

2. Bashmakov, V.N., Savenko, V.S., 1980. Izvestiia vuzov. Physics, 7: 29-32. (In Russian).

3. Kamyshanchenko, N.V., Neklyudov, I.M., 2010. On twinning of titanium VT1-0 after complete annealing. Metallovedenie i termicheskaya obrabotka metallov, 8: 25-29. (In Russian).

4. Tarasov, A.V., 2003. Metallurgy of Titanium. - Moscow: Akadem-kniga, 323p. (In Russian).

5. Paton, N.E., Backofen, W.A., 1969. Evidence for (101 $\overline{1})$ Deformation twining in Ti. TransAIME, p.1370.

6. Lii, Y., Reed-Hill, R.E., 1970. Some aspects of the variation of the strain anisotropy in Ti. - Met.Trans., 1: 447-453.

7. Kamyshanchenko, N.V., Neklyudov, I.M., Kuznetsov, D.P. et al., 2012. Influence of annealing at slow temperature cooling on structure and mechanical properties of technical titanium VT1-0.Promising materials, 3: 24-30. (In Russian).

8. Zwicker, U., 1979. Titanium and its alloys. Trans. from German. Moscow: Metallurgy, 512 s. (In Russian).

9. Tetelman, A.S., 1962. Acta Met.,10:831.

10. Simes, R., Delavignette, P., Amelinckx, S., 1968. Phil. Mag., 8:59.

11. Ostrikov, O.M., 2008. Mechanics of twinning of solids. / O.M. Ostrikov, Gomel: GSTU, 301p. (In Russian).

12. Cottrell, R.M., 1969. Accumulation of vacancies in pure and contaminated metals with a face-centered cubic lattice. "Defects in hardened metals" Moscow: Atomizdat, : 63-116. (In Russian).

13. Price, P.B., 1961. Phil.Mag. In the book. S.Amelinckx "Methods of direct observation of dislocations":449.

14. Price, P.B., 1961. Phys. Rev. Letters. In the book. S.Amelinckx "Methods of direct observation of dislocations", 6:615.

15. Price, P.B., 1961. Journ.Appl. Phys., In the book. S.Amelinckx "Methods of direct observation of dislocations", 32 :1746.

16. Bergheson, N., Fourdeux, A., Amelincks, S., 1968. Acta Met. In the book. S.Amelinckx "Methods of direct observation of dislocations", 9 : $464 \mathrm{p}$. 